\title{
Fouling layer characterization and pore-blocking mechanisms in an UF membrane externally coupled to a UASB reactor
}

\author{
Mónica L Salazar-Peláez ${ }^{1 *}$, Juan Manuel Morgan-Sagastume² and Adalberto Noyola² \\ 'Departamento de Ciencias Básicas, División de Ciencias Básicas e Ingeniería, Universidad Autónoma Metropolitana - Unidad Azcapotzalco. Av. San \\ Pablo 180, Col. Reynosa Tamaulipas, 02200, Ciudad de México, México \\ 2Instituto de Ingeniería, Universidad Nacional Autónoma de México (UNAM). Circuito Escolar s/n, Ciudad Universitaria, 04510, Ciudad de México, México
}

\begin{abstract}
A pilot-scale UASB reactor coupled with an external ultrafiltration (UF) membrane was operated under three different hydraulic retention times (HRT: 4, 8 and $12 \mathrm{~h}$ ) for municipal wastewater treatment in order to assess the composition and distribution of the fouling layer, as well as to identify the predominant fouling mechanisms. For that purpose, membrane autopsies were carried out based on fouling layer density determination, thermogravimetric, SEM and EDX analysis. Results showed a variable density of the fouling layer (average values were $13.90 \pm 0.22,13.46 \pm 1.15$ and $12.78 \pm 0.49 \mathrm{mg} / \mathrm{cm}^{2}$ for HRT of 4,8 and $12 \mathrm{~h}$, respectively), indicating that this parameter had an impact on the fouling density. Organic material was predominant in the fouling layer, being around $75 \%$ of its composition for the three HRT studied. Regarding pore-blocking mechanisms, standard blocking was the predominant mechanism at the beginning of filtration, coexisting at the end of it with cake filtration. In the first filtration cycle $(1 \mathrm{~h})$, after standard blocking, intermediate and complete blocking developed simultaneously during a short period of time and, finally, cake filtration prevailed. However, in the last ( $\left.19^{\text {th }}\right)$ filtration cycle, standard blocking and cake filtration occurred simultaneously from the beginning, suggesting the existence of an irreversible fouling layer, in spite of chemical cleaning.
\end{abstract}

Keywords: fouling layer density, pore blocking mechanisms, irreversible fouling

\section{INTRODUCTION}

Up-flow anaerobic sludge blanket (UASB) reactors have proven to be a viable technology for the treatment of municipal wastewater in developing countries and small communities based on their low investment, operation and maintenance costs (Foresti et al., 2006; Khan et al., 2011). However, anaerobic effluents often do not meet the discharge regulations or standards for water reuse, requiring a post-treatment step (Chernicharo et al., 2015).

Based on the acceptance of membrane aerobic bioreactors (MBR), the application of this concept to anaerobic processes has increased over the past decade. Some major advantages of this arrangement are total biomass retention, excellent effluent quality, low sludge production, a small footprint and potential for net energy production (Lin et al., 2013).

In this sense, it is worth noting that the removal of particulate organics by settling, adsorption, biodegradation and entrapment in the sludge bed of the UASB reactor makes it appropriate as a pre-treatment step for municipal wastewater when membranes are used, since municipal wastewater is generally characterized by a high particulate $\mathrm{COD} /$ soluble COD ratio. Thus, UASB reactors can be used as biofilters before membrane treatment, which could prevent the membrane from excessive exposure to high SS concentrations; however, the combination of membranes with different types of anaerobic high-rate reactor configurations, such as UASB reactors, should be further investigated (Ozgun et al., 2013).

Despite the advantages previously cited, membrane application to anaerobic processes for municipal wastewater treatment is limited by membrane fouling (Bérubé et al., 2006). Membrane fouling causes reduction in permeate flux,

To whom all correspondence should be addressed.

Im +525553189360; e-mail: monsalazar@correo.azc.uam.mx Received 6 October 2015; accepted in revised form 25 August 2017 and increases the transmembrane pressure (TMP), as well as causing a change in nominal molecular weight cut-off due to occlusion of the pores and the deposition of a fouling layer (Jiang, 2007). In addition, membrane fouling in anaerobic membrane bioreactors (AnMBRs) is not completely understood due to the complex nature of membrane foulants and diversity of operational conditions, membrane materials, configurations and wastewaters used in different studies (Ozgun et al., 2013).

Five strategies have been identified in order to control and minimize membrane fouling: (i) pre-treatment of membrane feed, (ii) optimization of operational conditions, (iii) modification of anaerobic sludge, (iv) modification of the membrane surface and $(\mathrm{v})$ restoration of membrane performance through cleaning operations (Lin et al., 2013). In the last case, the optimal choice of the cleaning procedure, which maximizes cleaning effectiveness and minimizes damage to the membrane, depends on both the membrane material and the fouling substances. For instance, an acidic cleaning agent is used to remove precipitated salts while an alkaline cleaning substance serves to remove organic matter (Al-Amoudi and Lovitt, 2007); if an inappropriate cleaning agent is chosen, membrane performance may be adversely affected and/or membrane deterioration may result.

Additionally, a proper selection of a fouling control strategy will be possible if the precise location of the fouling layer is known, both in the membrane filtration arrangement (which zone is mainly affected) and in the membrane itself (on the surface or within the pores). Thus, different types of fouling situations will require different control measures (Drews, 2010) and, consequently, a clear identification and differentiation among the pore-blocking mechanisms that occur during membrane filtration will be necessary in order to select a proper cleaning strategy (Choi et al., 2005).

The understanding of membrane fouling behaviour and mechanisms in AnMBR used for municipal wastewater treatment requires the assessment of several factors, such as 
membrane characteristics, operational conditions and sludge properties (Ozgun et al., 2013). In particular, the identification of the fouling mechanisms and the materials associated with pore obstruction and fouling layer formation are important research areas in AnMBR (Meng et al., 2009; Herrera-Robledo et al., 2011; Lin et al., 2013).

Therefore, the aim of this work was to analyse the density, composition and distribution of the fouling layer and to identify the predominant fouling mechanisms in a cross-flow ultrafiltration (UF) membrane externally coupled with a UASB reactor, based on the model proposed by Wang and Tarabara (2008).

\section{METHODS}

\section{Pilot plant}

The pilot plant has been described in a previous study (SalazarPeláez et al., 2011): a UASB reactor (700 L volume, PVC) was coupled with an external UF multitubular polyvinyldiene fluoride (PVDF) membrane module, with a $100 \mathrm{kDa}$ molecular weight cut-off (Abcor Ultracor, Koch Membrane Systems, USA). Each module had 7 tubular membranes of $3 \mathrm{~m}$ long and $1.27 \mathrm{~cm}$ diameter, with a total module surface area of $0.84 \mathrm{~m}^{2}$. A peristaltic pump (Masterflex 77410-10, Cole-Parmer, USA) was used to feed municipal wastewater into the UASB reactor, which was operated at ambient temperature and under 3 different hydraulic retention times (HRT), in increasing order: 4,8 and $12 \mathrm{~h}$. Each hydraulic condition was applied for 1 month without any discharge of sludge, other than the suspended solids in the effluent, resulting in a sludge retention time (SRT) of approximately $150 \mathrm{~d}$. A fraction of the UASB effluent was pumped to the external tubular UF membrane with a horizontal booster pump (H series, C48B800C09, $1 \mathrm{hp}$, Aermotor, USA). A new membrane module was installed for every HRT studied. TMP was measured with a pressure transmitter (Centripro, 0-689.5 kPa, USA). The experiment was carried out at constant pressure $(55.12 \mathrm{kPa})$ and cross-flow velocity (Vc: $2 \mathrm{~m} / \mathrm{s}$ ), under sub-critical conditions. Critical pressure $(136 \mathrm{kPa})$ was determined by the flux-step method (Le-Clech et al., 2006). A filtration cycle consisted of $23 \mathrm{~h}$ of filtration and $1 \mathrm{~h}$ of chemical cleaning using a sodium hypochlorite $(\mathrm{NaOCl})$ solution with a concentration of $300 \mathrm{mg} / \mathrm{L}$. The flux was recorded in $1 \mathrm{~min}$. intervals during the first hour of the filtration cycle and afterwards, in $1 \mathrm{~h}$ intervals until the end of the cycle. Filtration cycles were carried out during business days and the membrane was not operated on weekends; 19 filtration cycles were carried out with each HRT. The same pattern of membrane operation was applied for the three HRT studied.

\section{Membrane autopsies}

At the end of the operation with each HRT, autopsies were performed on the membrane modules. Each module (there were three modules, one for each HRT) was opened and a single tubular membrane of $2.7 \mathrm{~m}$ was extracted. Then, square pieces of $0.5 \times 0.5 \mathrm{~cm}$ were cut every $30 \mathrm{~cm}$. In order to obtain the weight per $\mathrm{cm}^{2}$ of the clean membrane, a new module was opened and the same procedure was followed.

\section{Determination of the fouling layer density}

The membrane pieces were dried at $102{ }^{\circ} \mathrm{C}$ for $2 \mathrm{~h}$. Then, dry weight and surface area were determined in order to calculate the density $\left(\mathrm{mg} / \mathrm{cm}^{2}\right)$ of each piece. To obtain the density of the fouling layer, the weight of the new membrane was subtracted from the density of the fouled membrane.

\section{Determination of the amount of organic and inorganic material in the fouling layer}

Dynamic thermogravimetric analyses (TGA) were performed in a thermogravimetric analyser (model Q500, TA Instruments, USA). The membrane pieces were weighed at room temperature using a microscale and subsequently heated at $10{ }^{\circ} \mathrm{C} / \mathrm{min}$ until reaching a temperature of $900^{\circ} \mathrm{C}$. The test atmosphere was purged with $\mathrm{N}_{2}(40 \mathrm{~mL} / \mathrm{min})$ in order to prevent oxidation or other undesired reactions.

\section{Scanning electron microscopy (SEM) analysis}

Selected membrane pieces were observed using a scanning electron microscope (JSM-6060 LV Model, JEOL, Japan) coupled with an Energy Dispersive X-ray analysis (EDX) system (Detector Si/Li, Inca-Sight Oxford, England). The fouled membrane pieces of $0.5 \times 0.5 \mathrm{~cm}$ were fixed with a glutaraldehyde solution (3\%) for $48 \mathrm{~h}$. Then, they were washed repeatedly with a phosphate-buffered saline (PBS) solution to remove any residual of glutaraldehyde and dehydrated by successive washes with ethanol dilutions in increasing concentrations (10\%, 30\%, 50\%, $70 \%, 90 \%$, absolute ethanol). Finally, the samples were freezedried and covered with a gold film for SEM observation.

\section{Determination of the pore-blocking mechanisms}

In order to assess the predominant pore-blocking mechanism at different filtration times, the linear equations developed by Wang and Tarabara (2008) were applied. Those equations were first proposed by Hermans and Bredée (1936) and describe 4 particular blocking mechanisms by colloidal particles: (i) complete pore blocking (also called pore sealing), (ii) standard pore blocking (also called pore constriction), (iii) intermediate pore blocking and (iv) cake filtration:

$$
\begin{aligned}
Q & =Q_{0}-K_{\mathrm{b}} V & & \text { Complete blocking } \\
K_{\mathrm{s}} t / 2 & =t / V-1 / Q_{0} & & \text { Standard blocking } \\
1 / Q & =1 / Q_{0}+K_{\mathrm{i}} t & & \text { Intermediate blocking } \\
K_{\mathrm{c}} V & =2 t / V-2 / Q_{0} & & \text { Cake filtration }
\end{aligned}
$$

where: $Q_{0}$ is the initial flow rate, $Q$ is the permeate flow rate, $V$ is the total volume of the permeate, $t$ is the filtration time and $K$ is the constant with the subscript indicating the blocking mechanism. Hernia (1982) demonstrated that the equations for the pore-blocking mechanisms could be derived from Eq. 5:

$$
\frac{\mathrm{d}^{2} \mathrm{t}}{\mathrm{dV}^{2}}=\mathrm{k}\left(\frac{\mathrm{dt}}{\mathrm{dV}}\right)^{\mathrm{n}}
$$

Where $k$ is a constant and $n$ is the blocking index, equal to $2,1.5,1$ or 0 for complete pore blocking, standard pore blocking, intermediate pore blocking and cake filtration, respectively.

Equations 1, 2, 3 and 4 were fitted to the experimental flux data using the linear least square fitting to identify the type, chronological sequence and relative importance of individual fouling mechanisms. The predominant poreblocking mechanism was defined by comparing the linear correlation coefficient $\left(R^{2}\right)$ of the graph obtained with each 
equation, taking a $R^{2}$ value of at least 0.99 as an indicator of a representative fouling mechanism.

Finally, it should be noted that the fouling definitions proposed by Meng et al. (2009) were adopted in this work: the removable fouling can be easily eliminated by implementation of physical cleaning (e.g. backwashing) while the irremovable fouling needs chemical cleaning. The irreversible fouling cannot be removed by any means, except that which would cause membrane damage.

\section{RESULTS AND DISCUSSION}

\section{Characterization of the fouling layer}

Figure 1 shows the density distribution and composition (percentage of organic and inorganic matter) of the fouling layer along the membrane modules for the three HRT studied (4, 8 and $12 \mathrm{~h}$ ).

The mean densities of the fouling layer were $13.90 \pm 0.22$, $13.46 \pm 1.15$ and $12.78 \pm 0.49 \mathrm{mg} / \mathrm{cm}^{2}$ for the HRT of 4,8 and $12 \mathrm{~h}$, respectively. Statistical analysis using the student's $t$-test showed a significant difference $(p<0.027)$ only between the first and last value, corresponding to the HRT of $4 \mathrm{~h}$ and $12 \mathrm{~h}$.

Based on this finding, a fouling layer with a higher density would be obtained at a shorter HRT in the UASB reactor. This result brings additional evidence of the dependency of the density of the fouling layer on the HRT applied. In a previous study with the same experimental arrangement, SalazarPeláez et al., (2011) found that the fouling rate and specific cake resistance increased with the reduction of the HRT, as a consequence of the higher concentrations of chemical oxygen demand (COD), total solids, extracellular polymeric substances (EPS) and soluble microbial products (SMP) as well as the decrease in the average particle size in the UASB effluent at the lowest HRT studied ( $4 \mathrm{~h}$ ). These findings are consistent with the results of Choo and Lee, (1998); Cho et al., (2005) and Farizoglu and Keskinler, (2006).

According to Drews (2010), the type, extent and structure of a fouling layer depend on the balance of transport forces of substances to and from the membrane, which, in turn, depend on the flux, tangential velocity and TMP. In this work, the filtration modules were operated at constant cross-flow velocity and TMP throughout the experiment and only the permeate flux varied, as a result of changes in resistance and density of the fouling layer. In other words, the characteristics of the fouling layer do not only depend on the variables identified by Drews (2010), but also on the type of substances that form the fouling layer and on operational parameters such as HRT.

Fouling can be classified into 3 major categories: biofouling, organic fouling and inorganic fouling (Spettmann et al., 2007). Biofouling is specifically related to the deposition and metabolic activity of bacterial cells on the membrane and includes the accumulation and adsorption of extracellular polymeric substances (EPS) and soluble microbial products (SMP); while organic and inorganic fouling refer to macromolecular species (proteins, polysaccharides, humic acids and other organic substances) and scale formation, respectively (Wang et al., 2014).

Thermogravimetric analysis showed that in the present experiment organic material was predominant in the fouling layer, accounting for approximately $75 \%$ of its composition for the three HRT studied. This result is in agreement with several reports in the literature: Herrera-Robledo et al. (2010) found that the cake layer in an AnMBR with a similar arrangement was mainly composed of volatile solids (85\%); similar results have also been reported by other researchers (Zhang et al., 2007; Wang et al., 2008; An et al., 2009).

The micrographs obtained from the fouling layer in the membrane modules (Fig. 2) reveal that the membrane surface was covered with a heterogeneous cake layer presenting amorphous and bacterial-like structures, as well as fissures. Micrograph (a) shows a compact fouling layer formed on the surface of the membrane, while micrograph (b) shows the growth of what appears to be a bacterial colony. In micrograph (c) numerous bacteria (bacillus and coccus) are fixed on a compact layer and (d) presents a similar arrangement with distinctive coccus structures forming the compact layer. Micrograph (e) shows an amorphous structure, possibly related to low-solubility elements (such as $\mathrm{Ca}, \mathrm{Mg}, \mathrm{Si}$ and $\mathrm{Fe}$ ). In micrograph (f) a dense and homogeneous layer shows cracks and fissures but no bacteria-like structures.
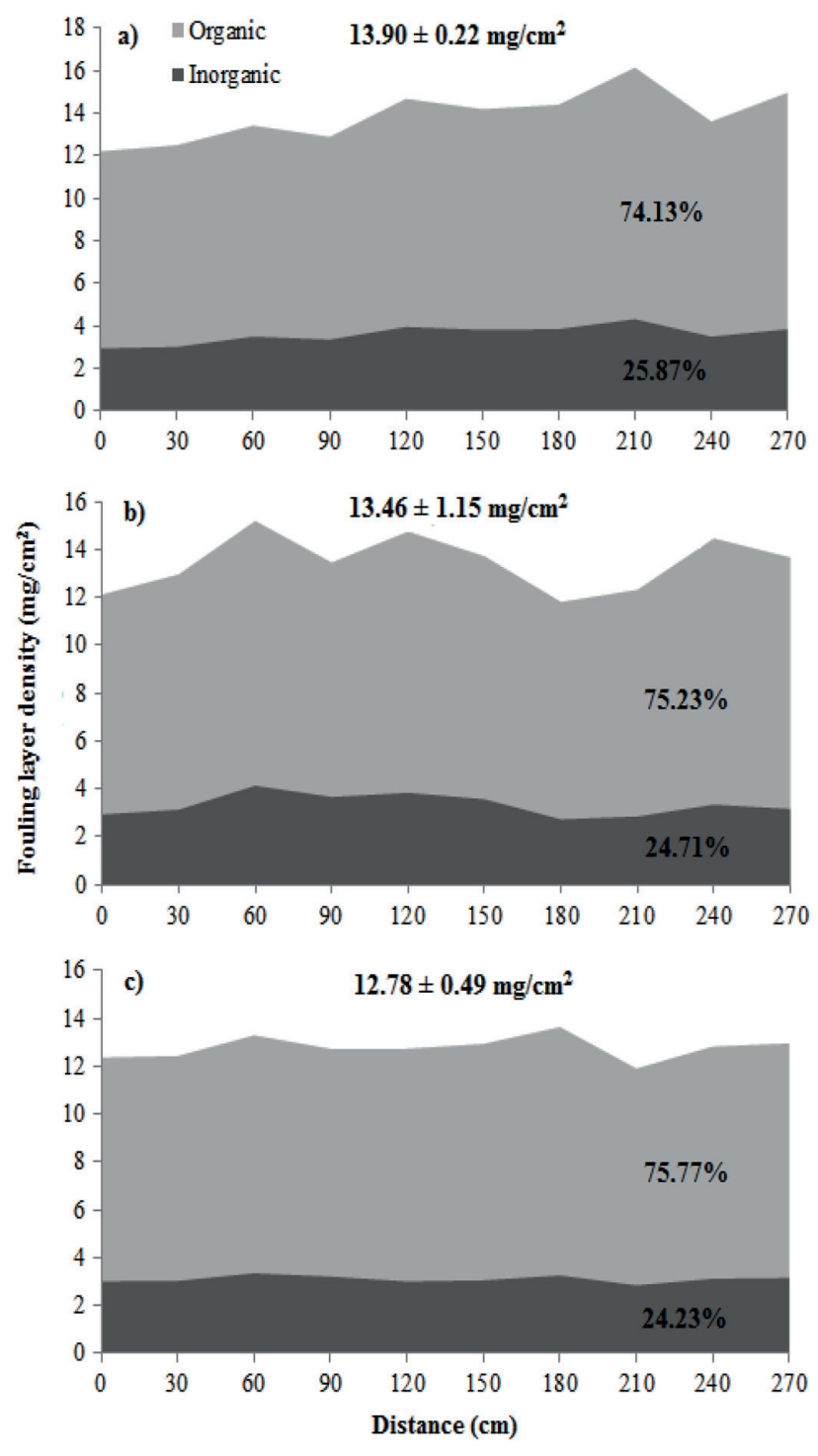

Figure 1

Density distribution and composition of the fouling layer along membranes for an HRT of a) $4 h$, b) $8 h$ and c) $12 \mathrm{~h}$. The mean value \pm standard deviation of the fouling layer density is shown in each graph. Bold numbers are the percentage of organic and inorganic matter in the fouling layer. 
Figure 3 shows the EDX spectra obtained for the three HRT studied. EDX analysis revealed the presence of S, K, Na, $\mathrm{Ca}, \mathrm{Mg}$ and $\mathrm{Fe}$ in the fouling layer. Si also appeared, possibly from grit in the raw wastewater. Lin et al. (2011) found that the cake layer in AnMBR was formed by organic substances and inorganic elements such as $\mathrm{Ca}(4.45 \%), \mathrm{S}(4.39 \%), \mathrm{Mg}$ (1.94\%), Al (1.72\%), Si (1.46), K (0.15\%). According to Wang et al. (2008) and Meng et al. (2007), inorganic elements such as $\mathrm{Mg}, \mathrm{Al}, \mathrm{Si}, \mathrm{Ca}$ and $\mathrm{Fe}$ play a key role in the formation of a fouling layer. These elements can bind to cells and bio-polymers previously deposited on the membrane and then form a dense fouling layer, even at their relatively low concentration (An et al., 2009).

Herrera-Robledo et al. (2010) suggested that these metals could precipitate at specific sites within the EPS matrix and these could act as heterogeneous epitaxic sites for further inorganic crystallization. Thus, during long-term UF runs of an UASB effluent, biological mineralization may produce biominerals by organic-inorganic interactions that would enhance the mechanical properties of the fouling layer. For the specific case of membrane fouling, EPS, SMP and lowsolubility inorganic material may produce inorganic crystals or amorphous precipitants, being part of a complex matrix of macromolecules that contribute to the formation of the skeleton on mature fouling layers, which are more resistant to conventional cleaning procedures.
Other elements identified in the fouling layer were $\mathrm{C}, \mathrm{N}$ and $\mathrm{O}$, associated with the organic material and bacteria deposited on the membrane surface. Also, $\mathrm{F}$ and $\mathrm{Cl}$ were found, probably due to the material of the membrane (PVDF) and sodium hypochlorite used in chemical cleaning procedures.

\section{Pore-blocking mechanisms}

In order to identify the type, sequence and relative importance of the pore-blocking mechanisms, the flux data obtained in the $1^{\text {st }}$ hour of the $1^{\text {st }}, 10^{\text {th }}$ and last $\left(19^{\text {th }}\right)$ filtration cycles associated with the UASB operating at $8 \mathrm{~h}$ HRT were used in Eqs 1, 2, 3 and 4 .

The filtration data obtained from this HRT was chosen since the operation of the UASB reactor at shorter HRT (4 h) had a detrimental effect on UF membrane performance as fouling rate and specific cake resistance increased sharply due to the enhanced production of soluble organic substances (Salazar-Peláez et al., 2011). The data were distributed in time intervals of $10 \mathrm{~min}$ in order to obtain the linear correlation coefficient $\left(R^{2}\right)$. Results are shown in Table 1 .

As Table 1 shows, the equations associated with cake filtration and standard blocking had the best fit $\left(R^{2}>0.99\right)$ to the data obtained during the $1^{\text {st }}$ hour of the selected filtration cycles, indicating that these two mechanisms prevailed at this filtration stage $(1 \mathrm{~h})$, regardless of the filtration cycle.

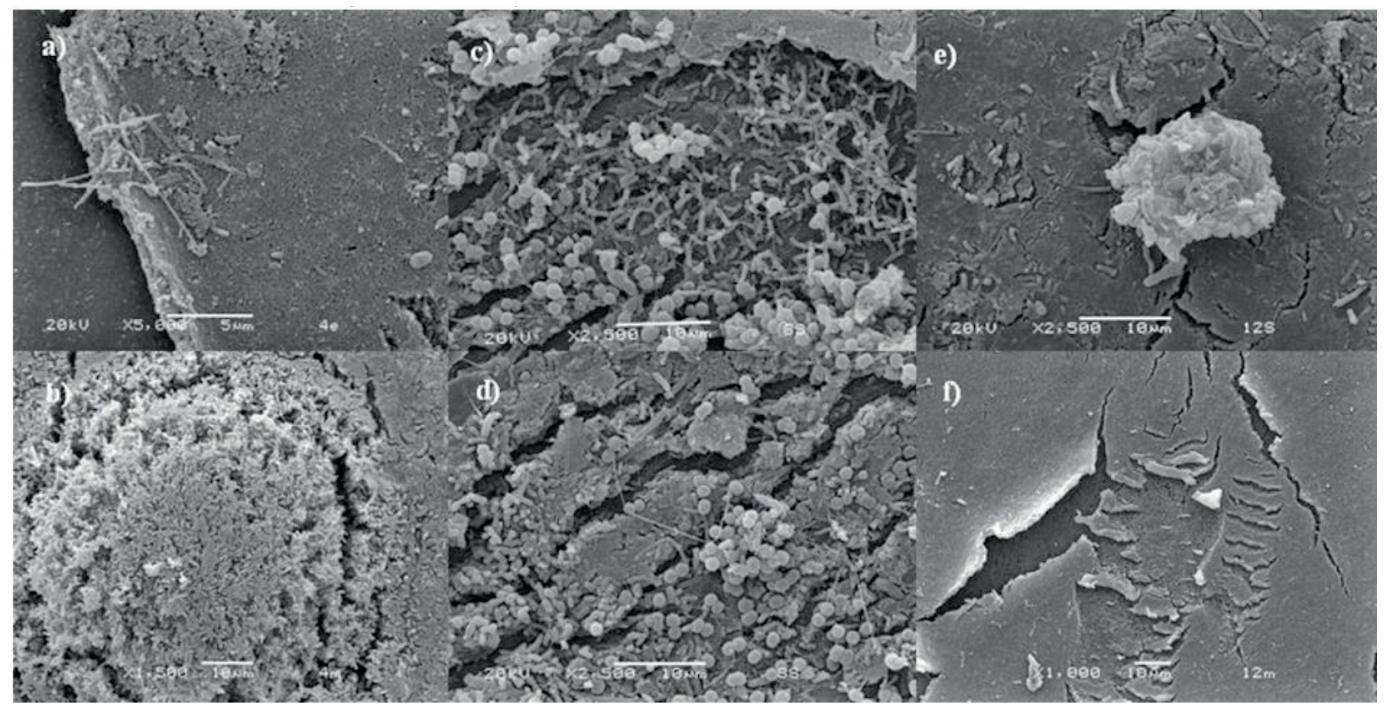

Figure 2

Micrographs of fouling layer formed on UF membrane; description in text

TABLE 1

Linearity coefficient $\left(R^{2}\right)$ for complete blocking (CB), intermediate blocking (IB), cake filtration (CF) and standard blocking (SB) for the $1^{\text {st }}$ hour of Cycles 1, 10 and 19 (UASB at 8 h HRT)

\begin{tabular}{|c|c|c|c|c|c|c|c|c|c|c|c|c|}
\hline \multirow{2}{*}{$\begin{array}{l}\text { Interval } \\
\text { (min) }\end{array}$} & \multicolumn{4}{|c|}{ Cycle 1} & \multicolumn{4}{|c|}{ Cycle 10} & \multicolumn{4}{|c|}{ Cycle 19} \\
\hline & CB & IB & CF & SB & CB & IB & CF & SB & CB & IB & CF & SB \\
\hline $0-10$ & 0.9581 & 0.9645 & 0.9528 & 0.9408 & 0.9400 & 0.9482 & 0.9594 & 0.9506 & 0.9795 & 0.9738 & 0.9636 & 0.9484 \\
\hline $10-20$ & 0.9153 & 0.9147 & 0.9959 & 0.9941 & 0.8922 & 0.8908 & 0.9921 & 0.9913 & 0.9753 & 0.9778 & 0.9972 & 0.9956 \\
\hline $20-30$ & 0.9217 & 0.9212 & 0.9997 & 0.9992 & 0.7557 & 0.7500 & 0.9987 & 0.9992 & 0.9755 & 0.9781 & 0.9990 & 0.9985 \\
\hline $30-40$ & 0.7986 & 0.7936 & 0.9991 & 0.9990 & 0.07560 & 0.7580 & 0.9964 & 0.9964 & 0.9439 & 0.9439 & 0.9992 & 0.9989 \\
\hline $40-50$ & 0.5000 & 0.5005 & 0.9995 & 0.9993 & 0.7500 & 0.7500 & 0.9991 & 0.9992 & 0.5025 & 0.5000 & 0.9990 & 0.9989 \\
\hline $50-60$ & 0.9266 & 0.9217 & 0.9994 & 0.9993 & 0.7680 & 0.7690 & 0.9985 & 0.9985 & 0.7500 & 0.7500 & 0.9994 & 0.9993 \\
\hline
\end{tabular}



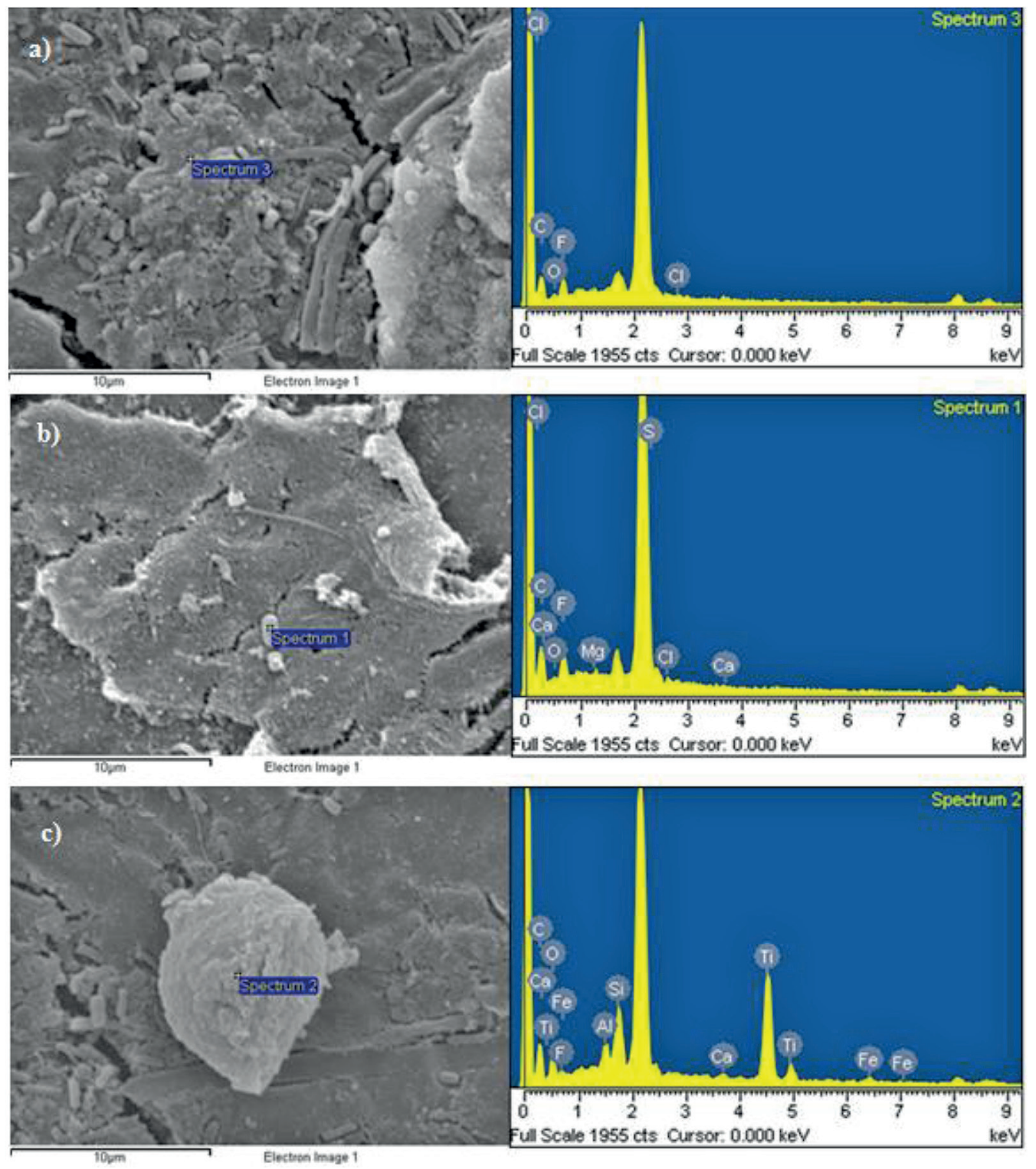

Figure 3

EDX spectra obtained at HRT a) $4 \mathrm{~h}$, b) $8 \mathrm{~h}$ and c) $12 \mathrm{~h}$. The corresponding micrograph shows the site on the fouling layer associated with the spectrum.

However, it is important to point out that during the initial interval of $0-10 \mathrm{~min}$, none of the equations presented a good fit. Apparently, at this early stage several pore-blocking mechanisms may take place on the membrane surface, without a clear predominance of any of them. Given the wide distribution of pore sizes of the membrane used in the experiment (Herrera-Robledo et al., 2010), it would be expected that some of the particles were deposited on other particles, while the rest of the particles could be deposited within the channels of the larger pores, thus two mechanisms could occur simultaneously.

However, the similarity of the $R^{2}$ values related to the mechanisms of cake filtration and standard blocking prevented the determination of their sequence during filtration. Consequently, the following analysis, proposed by Wang and Tarabara (2008), was performed: (i) for a given equation, the part (core) of the data with a $R^{2>} 0.99$ was identified, (ii) the core was expanded point by point, testing whether a point immediately adjacent to the core presented a $R^{2}>0.99$; if the $R^{2}$ value was below 0.99 the process ended and (iii) another equation was used for the remaining points, following the same data treatment.

Figure 4a shows the results of this analysis, representing the chronological sequence of the fouling mechanisms in the $1^{\text {st }}, 10^{\text {th }}$ and $19^{\text {th }}$ (last) filtration cycles, as a function of the accumulated volume of permeate and the percentage of flux decline.

As Fig. $4 \mathrm{a}$ shows, during the $1^{\text {st }}$ hour of the filtration cycle, the permeate volume obtained was $35.51 \mathrm{~L}, 32.18 \mathrm{~L}$ and $36.66 \mathrm{~L}$ for the $1^{\text {st }}, 10^{\text {th }}$ and last $\left(19^{\text {th }}\right)$ filtration cycles, respectively. Thus, in general terms, the main pore-blocking mechanisms were standard blocking (SB) and cake filtration (CF) for the three filtration cycles analysed. However, their contribution and time of appearance in each filtration cycle was different.

In the $1^{\text {st }}$ hour of the $1^{\text {st }}$ filtration cycle (new membrane), standard blocking occurred initially followed by cake filtration; 
then, over a small period, intermediate and complete blocking $(\mathrm{IB}+\mathrm{CB})$ as well as cake filtration developed simultaneously. According to Lin et al. (2013), membrane fouling is generally characterized by an initial pore constriction followed by cake formation and consolidation.

For the $10^{\text {th }}$ filtration cycle, neither intermediate nor complete blocking were detected, the main mechanisms being standard blocking for the beginning of the filtration cycle followed by cake filtration, which prevailed until the end of this cycle. In contrast, in the last filtration cycle $\left(19^{\text {th }}\right)$ both mechanisms (standard blocking and cake filtration) developed simultaneously from the beginning, indicating a sharp difference in membrane performance, in spite of the chemical cleaning with sodium hypochlorite applied after each filtration cycle. This result suggests that at the end of the experiment, irreversible fouling was present due to pore constriction and a remnant fouling layer, favouring the appearance of cake filtration from the beginning of the cycle, coexisting with standard blocking.

Based on the results presented in Table 1 and Fig. $4 \mathrm{a}$, a sequence of events may be proposed for filtration using a new UF membrane coupled with a UASB reactor under the operational conditions of this experiment: (i) in the first minutes, none of the four fouling mechanisms prevail, even if the flux declines at the highest rate; in this period, the concentrationpolarization effect may take a predominant place (Jiang, 2007); (ii) after $10 \mathrm{~min}$, standard blocking is the major fouling mechanism, indicating that partial obstruction inside the pores is taking place and, only in the $1^{\text {st }}$ filtration cycle, complete and intermediate blocking mechanisms occurred; (iii) the $1^{\text {st }}$ hour ends with a predominance of the cake filtration mechanism; (iv) during the successive filtration cycles, an irreversible fouling layer is built-up, which allows the simultaneous appearance of both standard blocking and cake layer mechanisms from the early stages of the last filtration cycle. Wang and Tarabara (2008) found similar results for dead-end filtration of colloidal suspensions with UF membranes.

Figure $4 \mathrm{~b}$ shows the fouling mechanisms as a function of the percentage of flux decline compared to the initial flux. The analysis of Fig. $4 \mathrm{~b}$ indicates that standard blocking was the main mechanism responsible for flux decline during the filtration cycles, ranging from 20 to $30 \%$ of decline regarding the initial flux, while less than $12 \%$ of flux decline was related to the cake filtration mechanism. The results in Fig. 4 would confirm that at the initial stages of a UF cycle, particles smaller than the membrane pores would enter and get trapped, reducing their effective filtration area (standard blocking), and resulting in a drastic flux decline. Then, bigger particles will be retained forming a cake layer, which will also contribute to the further retention of colloids and suspended solids.

\section{Flux behaviour}

Figure 5 shows the flux reduction vs. filtration time obtained at HRT $8 \mathrm{~h}$ for the entire filtration run (19 cycles).

In Fig. 5, each peak represents the beginning of a new filtration cycle of $23 \mathrm{~h}$ after a 1-h cleaning operation with sodium hypochlorite. After about $250 \mathrm{~h}$ of operation (13 cycles of filtration) the initial flux in the following filtration cycles decreased substantially and, consequently, so did the amount of permeate obtained. It is clear that the repetitive filtration cycles favoured the development of a fouling layer on the membrane surface, which became difficult to remove by the daily routine chemical cleaning with sodium hypochlorite, resulting in a limited permeate flux recovery. Apparently, the formation of irreversible fouling (not removed by chemical cleaning) took place in this experimental device in the last filtration cycles. This result is consistent with the findings presented in the previous section.

Herrera-Robledo et al. (2011), using a similar arrangement, found that a cleaning procedure using chlorine $(\mathrm{NaClO}$ at $300 \mathrm{mg} / \mathrm{L}$, for $30 \mathrm{~min}$ ) removed only $13 \%$ of the fouling layer, hypothesizing that the remnant fouling layer apparently was in part formed by biologically-induced mineralization materials, synthesized in part as a response to the cleaning procedure. The resultant biomineralized deposits were an important structural component within the remnant cake layer and may be the basis of irreversible membrane fouling.

Additionally, in each filtration cycle, permeate flux showed a typical behaviour for an MBR operated under constant TMP: a)

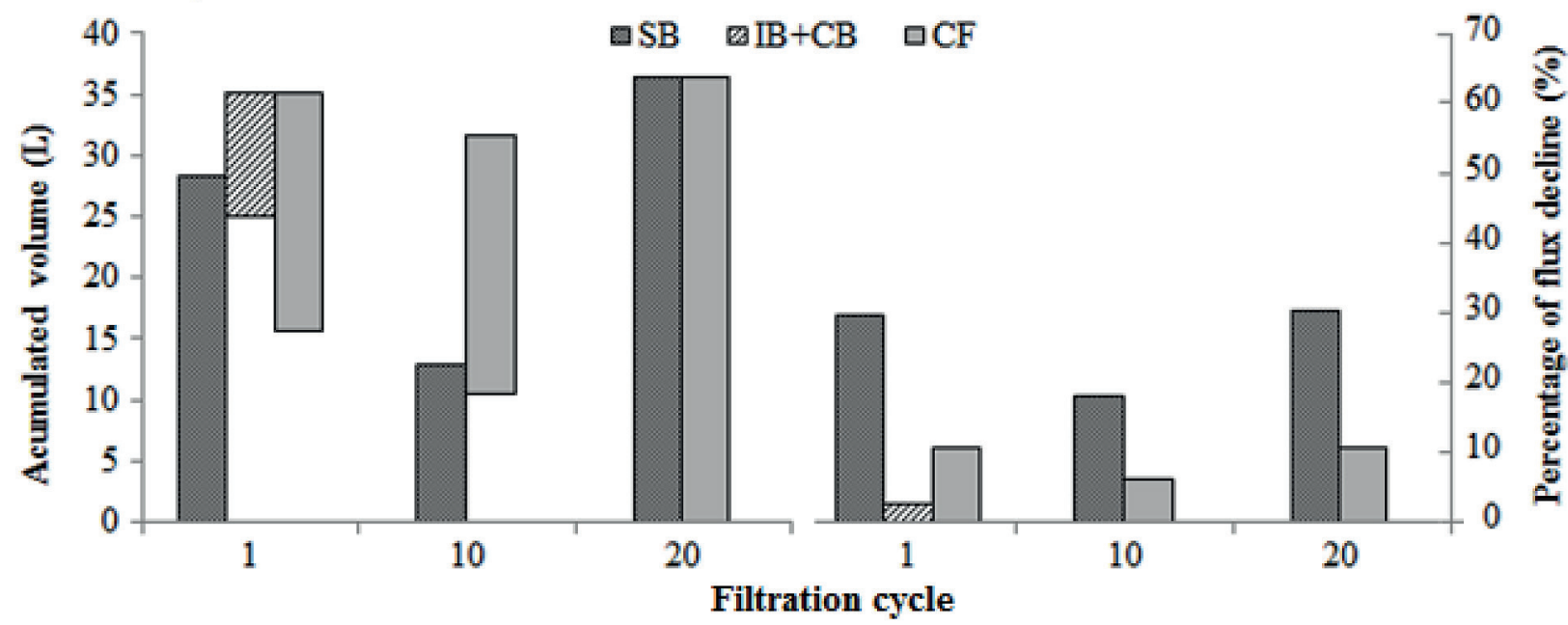

Figure 4

Contribution of each pore-blocking mechanism in the 1st hour of 3 filtration cycles, as a function of a) the accumulated volume of permeate and b) the percentage of flux decline (UASB at $8 \mathrm{~h} \mathrm{HRT}$ ) 


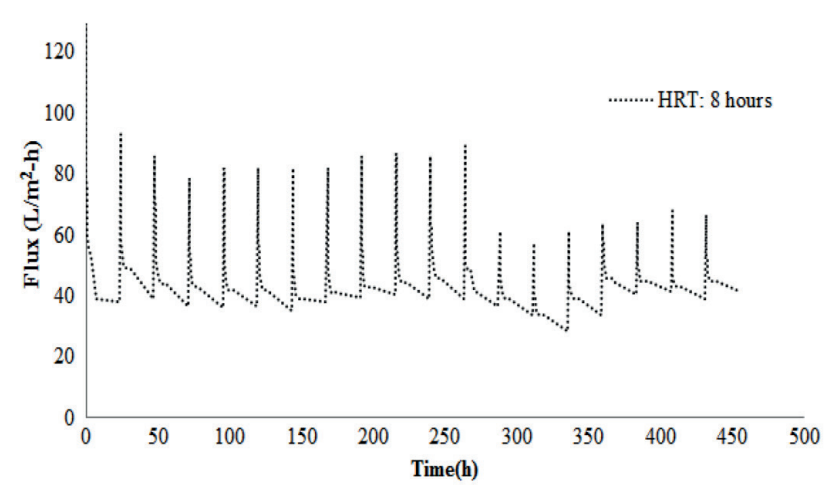

Figure 5

Flux behaviour obtained at HRT $8 \mathrm{~h}$

During the first minutes of the filtration a rapid flux decline occurred, then the rate of fouling decreased before reaching a plateau (Le-Clech et al., 2006).

According to Bae and Tak (2005), the main parameters affecting fouling during the first minutes of the filtration cycle would be the concentration/polarization interaction between the membrane material and the ionic compounds in solution, together with the irreversible deposition of the soluble fraction of the biomass suspension (presumably SMP). Accumulation of sludge particles on the membrane surface and on the previously deposited layers is the main phenomenon occurring during Phase 2 (10 to $30 \mathrm{~min}$ ) when the flux declines more slowly. In Phase 3 (after $30 \mathrm{~min}$ ), flux tends to stabilize, indicating that permeation drag and back transport have reached equilibrium. Although reduced permeation drag limits further severe fouling, compaction of the cake layer would play a significant role in the slight increase in filtration resistance observed during this last phase.

\section{CONCLUSIONS}

The mean densities of the fouling layer were $13.90 \pm 0.22$, $13.46 \pm 1.15$ and $12.78 \pm 0.49 \mathrm{mg} / \mathrm{cm}^{2}$ for the HRT of 4,8 and $12 \mathrm{~h}$, respectively, pointing out that the operation of the UASB reactor had an influence on the fouling density: a higher density fouling layer would be obtained at a shorter HRT in the UASB reactor. In addition, organic material was predominant in the fouling layer, being around $75 \%$ of its composition for the three HRT studied.

Standard blocking and cake filtration mechanisms prevailed during the filtration cycles associated with the HRT of $8 \mathrm{~h}$, although data analysis showed that in the last filtration cycle both fouling mechanisms were present from the beginning, suggesting the existence of an irreversible fouling layer, in spite of the applied chemical cleaning.

The main fouling mechanism, based on its contribution to flux decline during the first hour of the filtration cycle, was standard blocking. It was responsible for a 20 to $30 \%$ decline in the initial flux, while cake filtration contributed less than $12 \%$. However, at the end of the filtration run ( 19 cycles, $460 \mathrm{~h}$ ), the irreversible fouling developed on the membrane favoured the coexistence of standard blocking and cake filtration mechanisms.

\section{ACKNOWLEDGMENTS}

The authors acknowledge CONACyT (083679 project) for funding, Alicia del Real (CFATA-UNAM) for her assistance in SEM analysis and Roberto Briones (II-UNAM) for technical support. The first author thanks the Coordination of Postgraduate Studies (CEP-UNAM) for a scholarship.

\section{REFERENCES}

AL-AMOUDI A and LOVITT R (2007) Fouling strategies and the cleaning system of NF membranes and factors affecting cleaning efficiency. J. Membr. Sci. 303 (1-2) 4-28. https://doi.org/10.1016/j. memsci.2007.06.002

AN Y, WANG Z, WU Z, YANG D and ZHOU Q (2009)

Characterization of membrane foulants in an anaerobic nonwoven fabric membrane bioreactor for municipal wastewater treatment. Chem. Eng. J. 155 (3) 709-715. https://doi.org/10.1016/j. cej.2009.09.003

BAE T-H and TAK T-M (2005) Interpretation of fouling characteristics of ultrafiltration membranes during the filtration of membrane bioreactor mixed liquor. J. Membr. Sci. 264 (1) 151-160. https://doi.org/10.1016/j.memsci.2005.04.037

BÉRUBÉ P, HALL E and SUTTON P (2006) Parameters governing permeate flux in an anaerobic membrane bioreactor treating lowstrength municipal wastewaters: a literature review. Water Environ. Res. 78 (8) 887-896. https://doi.org/10.2175/106143005X72858

CHERNICHARO CAL, VAN LIER J, NOYOLA A and BRESSANI RT (2015) Anaerobic sewage treatment: state of the art, constraints and challenges. Rev. Environ. Sci. Biotechnol. 14 (4) 649-679. https:// doi.org/10.1007/s11157-015-9377-3

CHO J, SONG K-G, YUN H, AHN KH, KIM JY and CHUNG TH (2005) Quantitative analysis of biological effect on membrane fouling in submerged membrane bioreactor. Water Sci. Technol. 51 (6-7) 9-18.

CHOI H, ZHANG K, DIONYSIOU D, OERTHER D and SORIAL G (2005) Effect of permeate flux and tangential flow on membrane fouling for wastewater treatment. Sep. Purif. Technol. 45 (1) 68-78. https://doi.org/10.1016/j.seppur.2005.02.010

CHOO K-H and LEE C-H (1998) Hydrodynamic behavior of anaerobic biosolids during crossflow filtration in the membrane anaerobic bioreactor. Water Res. 32 (11) 3387-3397. https://doi.org/10.1016/S0043-1354(98)00103-1

DREWS A (2010) Membrane fouling in membrane bioreactors characterization, contradictions, cause and cures. J. Membr. Sci. 363 (1-2) 1-28. https://doi.org/10.1016/j.memsci.2010.06.046

FARIZOGLU B and KESKINLER B (2006) Sludge characteristics and effect of crossflow membrane filtration on membrane fouling in a jet loop membrane bioreactor (JLBRM). J. Membr. Sci. 279 (1-2) 578-587. https://doi.org/10.1016/j. memsci.2005.12.050

FORESTI E, ZAIAT M and VALLERO M (2006) Anaerobic processes as the core technology for sustainable domestic wastewater treatment: consolidated applications, new trends, perspectives, and challenges. Rev. Environ. Sci. Bio/Technol. 5 (1) 3-19. https://doi. org/10.1007/s11157-005-4630-9

HERMANS PH and BREDEE HL (1936) Principles of the mathematical treatment of constant pressure filtration. J. Soc. Chem. Ind. 55 (1) 1-4.

HERNIA J (1982) Constant pressure blocking filtration laws: application to power-law non-Newtonian fluids. Trans. Am. Inst. Chem. Eng., 60a 183-187.

HERRERA-ROBLEDO M, CID-LEÓN D, MORGAN-SAGASTUME JM and NOYOLA A (2011) Biofouling in an anaerobic membrane bioreactor treating municipal sewage. Sep. Purif. Technol. 81 (1) 49-55. https://doi.org/10.1016/j.seppur.2011.06.041

HERRERA-ROBLEDO M, MORGAN-SAGASTUME JM and NOYOLA A (2010) Biofouling and pollutant removal during long-term operation of an anaerobic membrane bioreactor treating municipal wastewater. Biofouling 26 (1) 23-30. https://doi. org/10.1080/08927010903243923 
JIANG T (2007) Characterization and modelling of soluble microbial products in membrane bioreactors. PhD thesis, Ghent University.

KHAN A, GAUR R, TYAGI VK, KHURSHEED A, LEW B, MEHROTRA I and KAZMI AA (2011) Sustainable options of post treatment of UASB effluent treating sewage: A review. Resour. Conserv. Recycl. 55 (12) 1232-1251. https://doi.org/10.1016/j. resconrec.2011.05.017

LE-CLECH P, CHEN V and FANE T (2006) Fouling in membrane bioreactors used in wastewater treatment. J. Membr. Sci. 284 (1-2) 17-53. https://doi.org/10.1016/j.memsci.2006.08.019

LIN H, LIAO B-Q, CHEN J, GAO W, WANG L, WANG F and LU $X$ (2011) New insights into membrane fouling in a submerged anaerobic membrane bioreactor based on characterization of cake sludge and bulk sludge. Bioresour. Technol 102 (3) 2373-2379. https://doi.org/10.1016/j.biortech.2010.10.103

LIN H, PENG W, ZHANG M, CHEN J, HONG H and ZHANG YE (2013) A review on anaerobic membrane bioreactors: Applications, membrane fouling and future perspectives. Desalination 314 (2) 169-188. https://doi.org/10.1016/j.desal.2013.01.019

MENG F, ZHANG H, YANG F and LIU L (2007) Characterization of cake layer in submerged membrane bioreactor. Environ. Sci. Technol. 41 (11) 4065-4070. https://doi.org/10.1021/es062208b

MENG F, CHAE S-R, DREWS A, KRAUME M, SHIN H-S and YANG F (2009) Recent advances in membrane bioreactors (MBRs): Membrane fouling and membrane material. Water Res. 43 (6) 1489-1512. https://doi.org/10.1016/j.watres.2008.12.044

OZGUN H, DERELI R, ERSAHIN M, KINACI C, SPANJERS H and VAN LIER J (2013) A review of anaerobic membrane bioreactors for municipal wastewater treatment: Integration options, limitations and expectation. Sep. Purif. Technol. 118 (1) 89-104. https://doi. org/10.1016/j.seppur.2013.06.036

SALAZAR-PELAEZ M, MORGAN-SAGASTUME JM and NOYOLA A (2011) Influence of hydraulic retention time on UASB posttreatment with UF membranes. Water Sci. Technol. 64 (11) 2299 2305. https://doi.org/10.2166/wst.2011.689

SPETTMANN D, EPPMANN S, FIEMMING H-C and WINGENDER $J$ (2007) Simultaneous visualisation of biofouling, organic and inorganic particle fouling on separation membranes. Water Sci. Technol. 55 (8-9) 207-210. https://doi.org/10.2166/wst.2007.260

WANG F and TARABARA V (2008) Pore blocking mechanisms during early stages of membrane fouling by colloids. J. Colloid Interface Sci. 328 (2) 464-469. https://doi.org/10.1016/j. jcis.2008.09.028

WANG Z, MAA J, TANG C, KIMURA K, WANG Q and HAN X (2014) Membrane cleaning in membrane bioreactors: A review. J. Membr. Sci. 468 (1) 276-307.

WANG Z, WU Z, YIN X and TIAN L (2008) Membrane fouling in a submerged membrane bioreactor (MBR) undersub-critical flux operation: membrane foulant and gel layer characterization. J. Membr. Sci. 325 (1) 238-244. https://doi.org/10.1016/j. memsci.2014.05.060

ZHANG J, PADMASIRI SI, FITCH M, NORDDAHL B, RASKIN L and MORGENROTH E (2007) Influence of cleaning frequency and membrane history on fouling in an anaerobic membrane bioreactor. Desalination 207 (1-3) 153-166. https://doi. org/10.1016/j.desal.2006.07.009 